\title{
DERECHO Y PODER
}

Sumario:. 1. Planteamiento de las relaciones entre derecho y poder; tesis principal. 2. Aportaciones de Theodor Geiger. 3. Contribuciones de Carl J. Friedrich al análisis de los fenómenos de poder. 4. Consideración final.

\section{Planteamiento de las relaciones entre derecho y poder; tesis principal}

Durante mucho tiempo, en otras épocas, el problema de la relaciones entre derecho y poder, expresado en estos términos, o también a veces indicado como el de las relaciones entre derecho y fuerza, anduvo bastante confuso y embarullado.

En una conferencia dada en 1918 , Stammler ${ }^{1}$ planteaba esta cuestión, al mismo tiempo que ejemplificaba los enredijos a la que ella había dado lugar, mediante la siguiente fábula. En la rama de un árbol está situada tranquilamente una mosca. Llega un gorrión, la coge y procede a desgarrarla. La mosca suplica por su vida. No, dice el asesino, tú eres mía pues yo soy grande y tú eres pequeña. Pero apenas había acabado de decir esto, un gavilán cae sobre el gorrión y lo destroza pronunciando las mismas palabras. Pero un águila se apodera del gavilán y contesta al pájaro al que acaba de herir con aquella misma frase. Sin embargo, el águila es alcanzada por la flecha del cazador y de nuevo suena el proverbio de aquel que posee el poder: "no puede ser de otra manera, porque yo soy grande y tú eres pequeño".

En el campo jurídico han luchado entre sí estos dos asertos. Mientras que uno dice "si tienes el poder, tienes el derecho sobre la tierra", otro replica "el supuesto derecho del más fuerte es lo más gravemente antijurídico". ${ }^{2}$

Stammler, al igual que muchos otros iusfilósofos, resuelve fácilmente el problema de un modo muy correcto. El derecho no es una cosa que exista en el espacio, ni es tampoco una energia física o biológica. El derecho, diríamos mejor, es una norma, un pensamiento teleológico de tipo imperativo. Por el contrario, el poder o, mejor dicho, la fuerza, constituye una energía o material o mental, que pertenece al mundo de los fenómenos reales.

Por eso resulta indebido y erróneo colocar derecho y poder sobre el

1 Véase Rudolf Stammler, "Recht und Macht", Rechtsphilosophische Abhandlungen und Vorträge, vol. II, Charlottenburg, 1925, pp. 123 ss. Lehrbuch der Rechtsphilosophie, Dritte Vermehrte Auflage, Berlin und Leipzig, 1928, pp. 40, 151-157.

2 Véase Eduardo García Máynez, El derecho natural en la época de Sócrates, México, 1939; Juan Llambias de Azevedo, El pensamiento del derecho y el Estado en la Antigüedad, desde Homero a Platón, Buenos Aires, 1956. Véase en estas obras las discusiones entre los sofistas sobre este tema. 
mismo plano, porque se trata de seres categorialmente distintos, que pertenecen a esferas diferentes, y entre los cuales no puede haber propiamente encuentros ni interferencias.

No tiene sentido hablar de oposición entre derecho y poder o fuerza. Cabe que se dé antítesis, que exista contradicción, entre un poder jurídico, esto es, que está de acuerdo con el derecho y que obra al servicio de éste, por una parte, y, por otra parte, un nudo poder como un simple hecho de fuerza corporal o psíquica que se manifiesta en contra de lo ordenado por el derecho. Así es de simple la cuestión. Por lo menos a primera vista según el planteamiento de Stammler.

Y si en lugar de referirnos al campo del derecho positivo, es decir, del derecho constituido, nos movemos en el plano de la estimativa jurídica, no tiene sentido contraponer justicia a poder, sino poder justo a poder injusto.

La solución del problema ha sido sencilla. Sin embargo, hay otras complicaciones que es preciso plantear y esclarecer.

El título formal de validez de una norma jurfdica en tanto que tal, es su pertenencia a un determinado orden de derecho. Ahora bien, aunque un orden jurídico aparecerá justificado ante la conciencia ética tan sólo cuando cumpla con los requerimientos de los principales valores que deben inspirarlo -así, por ejemplo, justicia, dignidad de la persona humana, libertades básicas de ésta, bienestar general, etc.-, sin embargo, un orden jurídico, es decir, un sistema de derecho positivo, es reputado formalmente válido en la medida en que cuenta con el apoyo del poder social predominante, que es el poder político. $O$, dicho con otras palabras, por debajo de la norma fundamental sobre la cual se basa todo el orden jurídico positivo, lo que encontramos es una realidad de poder social, mejor dicho, de poder político. Tanto es así, que un orden jurídico no puede ser reputado como formalmente válido si no tiene un minimum considerable de facticidad, esto es, de realización efectiva, o sea de eficacia de hecho.

$O$, expresando lo mismo de otra manera, cabe decir que la validez formal de las normas jurídicas está en alguna medida condicionada por su vigencia efectiva, por su eficacia real. ${ }^{3}$

Lo dicho no impide seguir distinguiendo entre el poder jurídico, esto es, el poder de acuerdo con el derecho establecido, por una parte, y por otra, el poder que obre en contravención de lo dispuesto por las normas jurídicas válidas y vigentes. En suma, se trata de la diferencia y antitesis entre poder jurídico y poder antijurídico, desde el punto de visa del derecho positivo.

Así como también en el plano de la estimativa o axiología podemos

3 Véase Luis Recaséns Siches, Introducción al estudio del derecho, México, 197o, pp. $44-45,65-66$, y $191-194$. 
y debemos seguir diferenciando entre un poder justo, es decir, un poder al servicio de los requerimientos de la justicia y de otros valores jurídicos, por una parte, y un poder que viole las exigencias de esos valores jurídicos, por otra parte.

Las aclaraciones hechas, aunque muy elementales, ponen de manifiesto dos puntos. El primero de esos puntos es el de que la sociología del derecho en gran parte constituye un segmento muy importante de la sociología del poder.

El otro punto es el de que una gran parte de la teoría general del Estado tiene que constituirse y desenvolverse como ciencia política que estudia los fenómenos de poder social predominante.

Aparte de los temas teóricos esbozados y aludidos, hay un motivo muy especial para ocuparse de nuevo de la cuestión de las relaciones entre el derecho y el poder, por virtud de una serie de acontecimientos, por cierto espeluznantes y superlativamente desagradables, que está viviendo la humanidad de nuestro tiempo. En el mundo de los hechos reales se está produciendo la práctica de una dosis abrumadora de explosiones de violencia, la cual no solamente es irracional, sino que se jacta de ser irracional, y de repudiar todo género de razones. Es éste un típico fenómeno de la crisis integral de nuestro tiempo, como fue también un hecho de enorme volumen en la crisis constituida por el tránsito del Medioevo a la Edad Moderna a través del Renacimiento.

Toda crisis comienza con una etapa de cinismo, por la renuncia a tener razón, por el hecho de que el mundo en que se vivió durante los siglos anteriores se ha venido abajo, lo cual fomenta morbosamente todas las posiciones negativas. En las épocas de crisis son frecuentes las posiciones falsas y consiguientemente los extremismos de todo género. Esto aconteció no sólo en el Renacimiento, antes bien sucedió asimismo en el tránsito de la Antigüedad pagana a la Antigüedad cristiana. ${ }^{4}$

En las épocas de crisis surge un asco indominable al mundo y al vivir, que se presenta con carácter puramente negativo. $Y$ en las crisis irrumpen no sólo los estallidos de violencia, sino que se establece una especie de culto en parte cínico y en parte hipócrita, a la violencia en tanto que violencia misma.

$Y$, por otra parte, un exceso de sobresalto, de alteraciones, sumerge al hombre en una mera naturaleza, lo animaliza, lo barbariza y determina que llegue a sentir asco y desesperación ante la vida. Propiamente desesperación es falta de esperanza. $Y$ al hombre inmerso en la crisis no se le ocurre ningún quehacer que le parezca satisfactorio; a nada que le parezca suficiente le incitan las cosas de su horizonte material y social ni las ideas

4 Véase José Ortega y Gasset, "En torno a Galileo", en Obras completas, tomo V, Madrid, 1947, 1946, pp. 11-164. 
de su horizonte intelectual. Seguirá siendo esto o lo otro, pero lo hará como un autómata, sin solidarizarse con sus actos que considera nulos, inválidos, sin sentido, aunque, con una especie de autohipocresía y de gesticulación escénica, intente atirmar a gritos lo contrario. En el fondo se encuentra abrumado por un asco indominable al mundo y al vivir. De aquí que del modo más inauténtico florezcan en la época de crisis todos los extremismos y se prediquen las más infantiles utopías.

Estos hechos suscitan la necesidad de un análisis renovado de las relaciones entre derecho y poder.

\section{Aportaciones de Theodor Geiger}

Geiger, uno de los pocos grandes sociólogos del derecho en nuestra época, ha producido renovados estudios sobre este tema, ${ }^{5}$ los cuales imperativamente deben ser tomados en cuenta. Theodor Geiger es no sólo un gran sociólogo del derecho, sino también un iusfilósofo eminente, y un destacado filósofo en términos generales.

Por de pronto Geiger indica que el problema sobre la relación entre poder y derecho ha sido puesto en una vía errónea por una filosofía ideológica. El pensamiento del Iluminismo dio ambos puntos como opuestos, el derecho como lo políticamente bueno, el poder como lo políticamente malo. Esto en parte depende de un concepto quimérico de la libertad.

La base consistía en un concepto de libertad absoluta. Se trataba de la independencia de la persona con respecto a otras personas. Ciertamente no como si se hubiese representado la libertad como arbitrio ilimitado; sino todo lo contrario. Pero los límites que quería poner a la libertad del individuo por razón de la convivencia social, no debían ser puestos por un individuo sobre otro. Aquí se celebra el maridaje de las ideas del liberalismo con las de la democracia. La limitación social del individuo es compatible con el contenido de la voluntad, sólo cuando la renuncia al arbitrio que pone en peligro a la totalidad se convierte de hecho en algo común para todos.

Los límites puestos al arbitrio deben ser precisamente los del derecho, es decir, no sólo compatibles con la idea de la libertad, sino precisamente dados por esa misma idea. Aquí radican componentes iusnaturalistas. Se cree, con la pretensión de justificada validez, que se puede decidir sobre qué fronteras deben ser puestas por el derecho al arbitrio del individuo, para garantizar la libertad de todos. Dentro de este círculo de ideas, el poder se convierte en una palabra indecente. El poder de uno significa la falta

5 Véase Theodor Geiger, Vorstudien zu einer Soziologie des Rechts, mit einer Einleitung und internationalen Bibliographie zur Rechtssoziologie, von Paul Trappe, Neuwied am Rheim und Berlin, 1964, pp. 337-376. 
de libertad de los otros. Ahora bien, la libertad y derecho están recíprocamente ligados de tal manera que el derecho es la condición de la libertad.

Frente a esta filosofía de los Siglos de las Luces, el pensamiento de la Anti-ilustración emprende la tarea de endiosar la idea del poder y de rendirle un culto supremo (filosofía francesa de la Restauración: de Maistre, Bonald; Romanticismo alemán: Hegel, etc.).

Aunque rechazando todo culto al poder, Geiger se lamenta de que haya tantos obstáculos mentales y sobre todo emotivos para proceder a un frío análisis de este tema.

Sin prejuicio del reconocimiento de la validez de juicios de valor sobre este asunto, sería de desear que los mismos no se interfiriesen en un sobrio y objetivo análisis de los hechos.

Hay una serie de factores que conducen, justificadamente, a pronunciarse en favor del derecho y contra el poder y la fuerza. Entre tales factores figuran el recuerdo de las doctrinas de Nietzsche, Sorel, Pareto y otros, la evocación de todos los abusos cometidos por los Estados totalitarios; y otra serie de sucesos desagradables.

Geiger dice que la relación entre derecho y poder depende de la definición que se dé del derecho y de la definición que se suministre del poder. Se podría ciertamente definir el derecho y el poder de tal manera que ambos apareciesen excluyéndose y oponiéndose de una manera recíproca.

Pero Geiger elige otro punto de partida: el ejemplo de que se afirma habitualmente que es misión del poder estatal cuidar del mantenimiento del orden jurídico. En esta frase obviamente derecho y poder no aparecen como opuestos, ya que el poder organizado e institucional debe obrar al servicio del derecho.

Quien diga que el derecho debe ir delante y por encima del poder, con lo cual parece establecer una oposición entre ambos, en el fondo significa otra cosa: significa que el derecho debe ir por delante y por encima, no del poder, sino de la arbitrariedad.

Ahora bien, la arbitrariedad es obviamente una auténtica oposición contra el derecho, en tanto que el derecho significa un orden preestablecido para el comportamiento humano, mientras que la arbitrariedad consiste en la irrupción del capricho o del interés personal sin obedecer a ninguna regla ni criterio de carácter general. ${ }^{6}$

Según Geiger, la palabra derecho designa prácticamente un orden de vida social de un gran complejo colectivo organizado centralizadamente, en tanto ese orden se apoya sobre un aparato sancionador manejado de modo monopolista por órganos estatales.

- Este concepto de la arbitrariedad por Geiger coincide con la teoría sobre la misma por Stammler, que ha sido generalmente aceptada por la mayoría de los iusfilósofos contemporáneos. 
Por poder, Geiger entiende lo mismo que Max Weber: la probabilidad de ser capaz de timonear o dirigir ciertos procesos de acontecimientos. Cuando los procesos de acontecimientos que se pueden timonear o dirigir son actos humanos, entonces los conceptos del derecho y del poder cabe que se encuentren el uno junto al otro; y cabe que se presenten mutuamente aunados o entrecruzándose. La determinación de lo uno y de lo otro pertenece al análisis empírico de la vida social.

Antes de proseguir la consideración de las relaciones entre derecho y poder, Geiger procede a establecer una serie de puntos.

Poder social es la probabilidad de ser capaz de dirigir la conducta de otra u otras personas. Existe una relación de poder, en tanto que una conexión interhumana está caracterizada por el hecho de que uno de los sujetos puede dirigir la conducta del otro. Tanto quien tiene el poder como quien es objeto del mismo cabe que sean individuos o grupos.

Son factores de poder las circunstancias sobre las cuales se basa la probabilidad de dirigir la conducta de otra persona. Estos factores son muy variados: fortaleza corporal superior, posesión de armas, astucia, disposición exclusiva sobre medios para la satisfacción de necesidades, atractivo sexual, don de sugestión o magnetismo, conocimiento de ciertos hechos o circunstancias, persuasión o convencimiento, etc.

Los factores de poder cabe clasificarlos en dos grupos: los primarios, dados por la naturaleza; y los secundarios, que son aquellos que se apoyan sobre el hecho de una organización social dentro de una estructura colecvita, por ejemplo, el poder del funcionario gracias a su manejo del aparato del Estado, el poder conectado con una posición de superioridad en el proceso económico de división del trabajo, etc.

Una relación de fuerza es una relación de poder en tanto que existe la probabilidad de dirigir la conducta de otras personas mediante el empleo de la coacción física o de la amenaza de ésta.

Una relación de poder es accidental, cuando se da entre dos individuos, y el factor de poder se apoya en las cualidades o circunstancias personales de ambos.

Categórica es una relación de poder, colectiva o individual, que existe entre dos personas en virtud de su pertenencia a grupos sociales - por ejemplo, la burocracia frente a la población; el soldado individual de un ejército vencedor frente al paisano individual del país enemigo; etc.

Frente a quienes poseen un poder sobre otro u otros, éstos pueden presentar una resistencia, la cual en determinadas condiciones cabe que resulte eficaz. Así pues, una relación de poder no es absoluta, sino de grado relativo.

Se puede hacer a un lado la consideración psicológico-social y fijarse predominantemente en las relaciones de poder categoriales colectivas; y en- 
tonces contemplamos esas relaciones, por ejemplo, entre estamentos, clases, estratos, partidos, grupos profesionales y económicos de toda índole, etc.

Cuando el miembro superior en una relación de poder intenta regular la conducta del miembro sometido, en cada caso según su capricho, su humor o su antojo del momento, entonces tenemos un régimen de arbitrariedad.

Adviértase la concordancia, en cuanto a la caracterización de la arbitrariedad, entre esta tesis de Geiger y la doctrina de Stammler sobre la diferencia entre mandatos arbitrarios y mandatos jurídicos.

Ahora bien, cuando se mantiene de una manera estable esa situación de poder arbitrario, entonces viene a establecerse una especie de regularidad, en parte en cuanto a las pretensiones de quien ejerce el poder, y en parte en cuanto a la adaptación del inferior. Podría decirse que en tal caso la habitualidad o consuetudinariedad crea una especie de regla, la cual aminora la situación de arbitrariedad imprevisible. Y con dicha regla viene en cierta manera a institucionalizarse la situación.

Tras ulteriores análisis, que no transcribo aquí, Geiger establece estas observaciones: $x$ ) los cambios de equilibrio de los factores primarios de poder se manifiestan sólo cuando son lo suficientemente grandes para superar la tendencia a la permanencia de los factores secundarios (por ejemplo, la rutina) ; 2) los cambios de equilibrio menores de los factores primarios de poder consiguen influencia en la situación de poder, sólo cuando son de. carácter permanente y se establecen con vistas a una larga duración.

Ahora bien, cabe que una cierta constelación de nexos de poder de una persona o de un grupo tenga la posibilidad de dictar y ejecutar disposiciones que no se relacionan con otras personas o grupos particulares dentro del complejo colectivo total, sino que determinan y someten la totalidad de dicho complejo.

Cuando se da dicha situación total de poder, en la que unos mandan y otros obedecen, entonces se habla de una relación de dominio, de imperio o de gobierno.

El dominio o imperio es arbitrario cuando se produce con ausencia de toda regla.

$\mathrm{Si}$, por el contrario, el dominio o imperio obedece a una situación ordenada por ciertas reglas, entonces hablamos de un dominio, gobierno o imperio del derecho.

Titulares del imperio, del dominio o del gobierno son las personas o los grupos que han monopolizado el poder integral para sí propios. Se llaman súbditos las personas sobre las cuales se ejerce el poder integral.

La estructura del imperio, gobierno o dominio de un Estado viene determinada: a) por el hecho de quien es el titular del dominio o imperio; b) por el modo como el imperio o dominio está distribuido entre los di- 
versos titulares de aquél; $c$ ) por el hecho de cuales sean las disposiciones y condiciones que hagan posible el imperio o dominio; $d$ ) por la manera según la cual sean percibidas organizadamente las disposiciones del imperio, gobierno o dominio.

En el transcurso de la historia se han producido siempre nuevos grupos o combinaciones de ellos, unas veces con éxito y otras sin él, que se han esforzado en conseguir el monopolio del poder integral, de conquistarlo, de apoderarse del mismo, de obtener participación en él o de destruirlo. A todos esos hechos se les comprende bajo la denominación de la lucha por el poder. Su objeto es el dominio, gobierno o imperio.

Las personas o los grupos que han adquirido un monopolio del poder integral desarrollan un aparato de imperio, gobierno o dominio con los correspondientes medios estatales para la ejecución de sus mandatos. Mediante el control de este aparato crean una situación clave para sí mismos.

Este aparato mismo es una especie de baluarte del dominio. Este aparato indica un conjunto de relaciones humanas, de rutinas reforzadas por la inercia, una especie de dinámico tejido de acciones correlacionadas, a veces de modo muy complicado. Todo esto contribuye a dar a dicho aparato una notoria fortaleza. Se ha dicho que es mucho más fácil elevar un rey al trono que hacerlo bajar de él. Sencillamente porque el trono es una especie de cúspide de una maquinaria de relaciones e interrelaciones muy complejas, la cual constituye el aparato del dominio o imperio.

En los regímenes aristocráticos, en los cuales la nobleza propietaria de la tierra, que es la titular del poder político, ya bien sola, ya quizá en concurrencia constitucional con un rey, no todos sus componentes actúan de manera conjunta, ligados por una solidaridad unitaria. El ejercicio del dominio radica más bien en parte en las manos de algunos exponentes individuales del estamento imperante, en parte en mecanismos de tipo burocrático. En regímenes de democracia representativa no todos los diputados ejercen un igual poder, antes bien el poder se halla predominantemente en manos de un grupo profesional de parlamentarios.

Todo orden jurídico necesita del poder para su existencia real.

Pero hay algo más todavía. Un orden jurídico viene a representar la expresión o traducción al lenguaje normativo en unas estructuras efectivas del poder político.

Desde luego que lícitamente el poder debe actuar como soporte y como agente de un derecho justo. Esto constituye un postulado evidente, que no es necesario discutir. Pero con independencia de este principio irrefragable, si observamos las relaciones genéticas entre poder y derecho, es decir, si atendemos a la sucesión cronológica del uno y del otro, habremos de reconocer que el poder precede al derecho. Según se indicó ya, todo orden jurídico viene a constituir la transcripción normativa de unas relaciones efec- 
tivas de poder, y más concretamente de poder político. Entonces resulta que, aun cuando desde el punto de vista estimativo o axiológico el poder deba ser un instrumento al servicio del derecho justo, en la secuencia real de los fenómenos, el poder precede al derecho. En toda sociedad, aun antes de haber sido organizada jurídicamente, se da un poder. Lo mismo ocurre en dimensiones más grandes con las sociedades políticas. El poder político precede o antecede cronológicamente al derecho. El poder político viene a decantarse en normas jurídicas cuya efectividad intenta garantizar.

No se puede decir en términos generales que,el derecho sea lo contrario del poder. El contenido del orden jurídico, la totalidad de las figuras de conducta sancionadas por éste, depende en alto grado de la estructura del poder que tenga la sociedad. Ahora bien, lo que diferencia una situación jurídica frente a una situación de mero poder es el hecho de que en aquélla, la situación jurídica, no se actúa según el capricho del momento, sino de acuerdo con reglas establecidas. Referido al concepto del poder, el derecho es una modalidad del ejercicio del poder, es una regulación de las relaciones de poder. La situación jurídica no es lo contrario de la situación de mero poder, sino que es la situación de un poder normado. El derecho significa, referido a las relaciones internas de poder de una sociedad, que el timoneaje de la conducta humana se produce por vías reguladas.

\section{Contribuciones de Carl J. Friedrich al análisis de los fenómenos de poder}

Carl J. Friedrich ha contribuido en nuestros días al desenvolvimiento de la ciencia política con una obra realmente monumental. Empleo este adjetivo para subrayar la importancia de este trabajo de Friedrich, contenida en parte en un volumen publicado en alemán $\mathrm{y}$, en parte, en otro libro sacado a luz en lengua inglesa.?

Estoy muy de acuerdo con el sentir predominante en la filosofía de nuestro tiempo de que debe hacerse no sólo una filosofía de la vida, sino también una filosofía para la vida; es decir, que la teoría es superlativamente práctica; y que la práctica sin teoria se pierde en la oscuridad y en el vacío. ${ }^{8}$

En el presente artículo, el cual intenta tan sólo constituir una introducción al tema de las relaciones entre derecho y poder, resumiré algunas de

7 Véase Carl Joachim Friedrich, Politik als Prozees der Gemeinschaftsbildung: Eine empirische Theorie, Köln und Opladen, 1970; Man and His Government —an Empirical Theory of Politics, Nueva York. 1963.

8 Sobre el poder político, han escrito, entre otros: Georges E. J. Catlin, The Science and Method of Politics, 1927; A Study on the Principles of Politics, 1930; Charles E. Merriam, Political Power: Its Composition and Incidence, 1934; Bertrand Russell, Power: $A$ New Social Analysis, 1938; Harold D. Lasswell, Politics, Who Gets What, When, and How, 2. ed., 1958; Bertrand de Jouvenel, Du Pouvoir, 1945; Floy Hunter, Community Power Structure, 1953 . 
las observaciones más incitantes y más fértiles presentadas por Friedrich en sus mencionadas obras.

Se trata de habérnoslas con la realidad efectiva de lo político. Es necesario hacerlo constar así para mantener la diferencia básica entre la política y la economía.

El poder no es propiamente una cosa material ni mental, antes bien consiste en una especial relación, como ya lo observó certeramente Locke. ${ }^{9}$ Cuando se habla de poder nos referimos al poder sobre otros hombres, lo cual se evidencia clarísimamente en la máxima manifestación del poder, que es poder político, lo mismo en la consecución de éste que en su decadencia.

Claro que, aun reconociendo que el poder es una relación, desde otro punto de vista, cabe considerar que el poder es también la posesión de determinados medios para influir sobre la conducta ajena. Se puede decir que el poder es aquella relación interhumana la cual se hace patente en la conducta de observancia o seguimiento. Seguimiento significa que A, B, C, etc. hacen lo que $\mathbf{F}$ desea.

El poder se manifiesta no sólo mediante mandatos de quien lo detenta, dirigidos a quienes le están sometidos, sino también, en la mayoría de los casos, por convencimiento, por sugestión e influencias de los más variados jaeces.

Cabe que nos interroguemos por la fuente del poder. Esta pregunta puede contestarse diciendo que prácticamente todas las cosas a las cuales los hombres atribuyen algún valor pueden convertirse en fundamento de una relación de poder. $\mathrm{Y}$ ciertamente esto puede suceder de dos maneras: una de esas maneras consiste en que varios hombres se asocien formando un grupo para conseguir determinado bien; y la otra manera estriba en que algunos de ellos poseen ese bien y están en situación de conceder algo del mismo, que los otros apetecerían poseer. Así la mayor parte de los hombres desean protección contra la violencia, pero en la historia la mayor parte de las veces han sido pequeños grupos los que se encontraron en situación de proporcionar esta protección. Incluso en los casos de conquista, el conquistador es quien puede dar protección a los conquistados.

Este deseo de protección contra la violencia ha servido para racionalizar el poder político, para justificarlo y explicarlo teóricamente, sobre todo mediante las llamadas teorías contractualistas que tanto auge tuvieron en los siglos xviIl y xIx, aunque sus orígenes sean muy remotos y sus desenvolvimientos a través del Medioevo resulten muy interesantes. ${ }^{10}$

9 Véase John Locke, An Essay Concerning Human Understanding, 1687, libro II, cap. 21. Essays on Civil Government, 169o, libro 2, p. 4.

10 Véase Luis Recasáns Siches, "Las teorías políticas de Vitoria, con un estudio sobre el desarrollo de la idea del contrato social", en Anuario de la Asociación Francisco de 
Friedrich establece muy correctamente una diferencia entre poder coercitivo y poder consensual. El coercitivo se basa sobre la amenaza del empleo de la fuerza para imponer a todo trance las órdenes o mandatos de quien posee el poder. Por el contrario, el poder consensual deriva principalmente del asentimiento de los gobernados.

A este respecto resulta oportuno recordar las observaciones de José Ortega y Gasset ${ }^{11}$ de que quien manda normalmente es la opinión pública. Cuidémonos de evitar la caída en el error de interpretar el fenómeno del poder político como pura relación de violencia material. El poder político es cosa muy distinta de la fuerza física. Aun cuando el poder político maneje resortes de fuerza corporal y mecánica, tales resortes no constituyen la raíz de dicho poder, sino que son meros instrumentos que él maneja, los resortes de fuerza, por ser precisamente poder social, ya que, de otra suerte, no dispondría de ellos. En fin de cuentas el poder político se funda sobre factores de conciencia. No consiste puramente en la posición de vigor corporal de las armas, del dinero y de otros elementos materiales, sino en la obediencia de las personas que manejan las armas y que aceptan el dinero como medio de pago.

Quien cuente tan sólo con la brutalidad de la fuerza material podrá dirigir una agresión contra un pueblo, incluso sostenerla durante algún tiempo, pero propiamente no ejercerá un mando político sobre el mismo; y muchísimo menos de un mando que pueda ser calificado como jurídico. El poder político, por el hecho de mandar jurídicamente, dispone de la fuerza para imponer sus normas a los individuos rebeldes. Pero el hecho global de su mando o, lo que es lo mismo, el fundamento del sistema jurídico del régimen como totalidad, no tiene que ser la fuerza, sino que tiene que ser una adhesión de la comunidad nacional.

El fundamento de la vigencia de un sistema político-jurídico no consiste en una pura relación de fuerza. Por el contrario, consiste en gran medida en una de las resultantes que forman la textura social. El mando político jurídico tiene a su disposición la mayor concentración de poder'y de fuerza que hay en la sociedad para hacer cumplir inexorablemente, impositivamente, si es preciso, sus mandatos y preceptos. Pero el mando jurídico no se funda en la tenencia de los instrumentos de fuerza material, sino en un apoyo de la opinión pública. Precisamente porque un régimen se instala con la aquiescencia de la opinión pública, porque cuenta con la

Vitoria, 1931; "Historia de las doctrinas sobre el contrato social", en Revista de la Escuela Nacional de Jurisprudencia, t. III, no 12, México, 1941, pp. 331-360.

11 Véase José Ortega y Gasset, La rebelión de las masas, en Obras completas, tomo IV, especialmente, pp. 231-275; Luis Recaséns Siches, Introducción al estudio del derecho, 197o, pp. 65-71; Tratado general de filosofia del derecho, $4^{\mathrm{a}}$ edición, 1970, pp. 301-304, 345-346, 352-359; Experiencia juridica, naturaleza de la cosa y lógica "razonable"; 1972, pp. 161-162, $169-181$. 
resultante de las voluntades que integran la colectividad, precisamente por eso tiene a su disposición el aparato coercitivo.

O dicho con las palabras de Friedrich, en la inmensa mayoría de los casos del poder político se da preponderantemente una dimensión consensual, es decir, el asentimiento de quienes están dispuestos a obedecer por las buenas las órdenes y las normas del mando jurídico político.

Sin embargo, cuando se habla de poder netamente coercitivo por un lado y de poder consensual por el otro, lo que se hace es referirnos a casos tipo. En la realidad unas veces andan mezclados unos componentes básicos de consentimiento con otros resortes debidos a la amenaza de la coacción impositiva; coerción y consentimiento son más bien, ambos, componentes que se dan en casi todas las situaciones de poder.

Según que predomine el asentimiento de los mandados hablamos de un poder consensual. Si, por el contrario, prepondera el miedo a la fuerza entonces hablamos de un poder coercitivo. Pero repito que sería muy difícil encontrar situaciones caracterizables en total como pertenecientes sólo a uno de esos dos tipos. Lo corriente es la combinación de elementos de ambos tipos, aunque normalmente, salvo en los casos que Ortega llama de agresión a un pueblo, lo que suele predominar es el consentimiento de los mandados.

Por otra parte, hay que notar que las cosas son más complicadas de lo que pudiera parecer a primera vista. No hay una sola manera de coacción ni hay tampoco una sola forma de asentimiento.

Mediante la investigación de los hechos políticos se puede distinguir tres clases de coacción: física, económica y psíquica.

Ejemplos de coacción písiquicos los encontramos en muchos tipos de propaganda y en los casos que Max Weber llama de dominación carismática.

Tanta es la importancia de la propaganda que los Estados totalitarios organizan el monopolio de los medios de comunicación e información.

En muchos casos, en el poder ejercido por la propaganda, se hace difícil discriminar entre los elementos coercitivos y los consensuales. Es decir, es así porque la propaganda trata de inducir en un determinado sentido el interés y los deseos de sus destinatarios, por lo tanto, de lograr un asentimiento o sea una disposición consensual. Pero en el origen de esa disposición consensual encontramos el factor bastardo de ciertos medios deshonestos de propaganda que tratan de subyugar al subconsciente. Recuérdense los hechos puestos en claro por Vance Packard en su famoso libro Los persuasores ocultos. ${ }^{12}$

En lo que se refiere al consenso de los mandados, encontramos múltiples $y$ variados matices, de los cuales me he ocupado yo en otros trabajos. ${ }^{13} \mathrm{Re}$ -

12 Véase Vance Packard, The Hidden Persuaders, 1958; Luis Recaséns Siches, Tratado general de sociologia, 12a. ed., 1973, pp. 360-362.

13 Véase las obras citadas en la nota 11 . 
sumiendo, cabría decir que el poder consensual va desde el apoyo entusiasta y fervoroso hasta la tolerancia renuente y desganada.

A este respecto observa Friedrich que las posibilidades de producir consenso son tantas como valores haya.

La cuestión sobre la producción de consentimiento plantea el problema de la dirección, conducción, liderazgo o caudillaje político.

Friedrich dice que hay tres tipos principales de liderazgo político, a saber: el renovador, el conservador y el protector. Cada una de estas tres formas corresponden a modos característicos del seguimiento, obediencia y aplauso al líder.

El iniciador o renovador, el conquistador, el emprendedor o el legislador, abre nuevos caminos a la acción política que suscitan el entusiasmo de quienes lo siguen. Se trata de un liderazgo renovador que crea nuevas valoraciones.

El liderazgo conservador actúa para mantener en pie el orden existente, y para ello acentúa los métodos ya en práctica del comportamiento politico, métodos con los cuales se encuentran familiarizados sus partidarios.

El liderazgo protector garantiza a quienes lo siguen seguridad, ante todo seguridad contra el aniquilamiento físico; pero más allá asegura también una determinada forma de vida, una cultura y sus valores, unas convicciones y unos intereses.

Las tres formas de liderazgo o caudillaje son capaces de suscitar asentimiento, por lo tanto, de convertirse en la base del poder consensual.

Friedrich subraya que con esta clasificación se refiere él a los tipos de liderazgo; mientras que Max Weber ${ }^{14}$ en su famosa clasificación de mando tradicional, mando carismático y mando racionalizado, toma en cuenta más bien las formas de dominación política.

Por otra parte, Friedrich distingue entre el simple poder, cuyos diversos tipos se caracterizan según cuál sea su origen, por una parte, y por otra el liderazgo o caudillaje político.

Cuando el poder va en progresivo aumento, cuando se organiza, cuando se institucionaliza, los medios o resortes de ese poder se incrementan.

El poder en aumento suele tropezar con variados obstáculos, entre ellos, el surgimiento de un contrapoder, es decir de un poder que trata de oponerse al que está creciendo. A veces se llega a situaciones de equilibrio entre los poderes que se manifiestan.

A continuación Friedrich estudia el problema de las relaciones entre el poder y los valores. Pero, por de pronto, asienta la tesis de que en el poder encarna un valor. Esto lo subrayó ya Hobbes. ${ }^{15}$

Claro que se plantea el problema capital de las relaciones entre jus-

14 Véase Max Weber, Wirtschaft und Gesellschaft, $2^{\text {a }}$ ed., 1925, $3^{\text {a }}$ parte, cap. 9 .

15 Véase Thomas Hobbes, Leviathan, 1651, cap. 11. 
ticia y poder. Es obvio que hemos de proclamar que el poder debe ponerse al servicio de las exigencias de justicia. Ya $\mathrm{Pascal}^{16}$ dijo que sin poder no hay justicia.

Otro de los temas conexos es el fenómeno de la corrupción: parece que un poder absoluto tiende casi siempre a corromperse, por lo cual conviene establecer límites y controles para el poder.

Las formas del poder se transforman fácilmente, lo mismo las del poder predominantemente coercitivo que las del poder predominantemente consensual. En el primero, éste puede transformarse de coercitivo material en coercitivo psíquico y económico.

En cuanto al poder político, la cuestión medular es la de cómo se pueda lograr la colaboración de varios hombres por razón de finalidades comunes.

Hasta aquí se ha hablado simplemente de poder politico y también de liderazgo o caudillaje. Pero hay que añadir a lo dicho el concepto de otra realidad: la dominación, el señorío o el imperio, realidad que puede ser expresada con la palabra gobierno. Esta realidad aparece cuando la dominación se institucionaliza, se convierte en algo consuetudinario, y cuando es estructurada. En términos generales, se entiende como estructura una relación afianzada y ordenada de las partes entre sí, tal y como se dan en un edificio. En fin de cuentas, este concepto deriva de la arquitectura. Pero antes de que el poder sea estructurado, debe ser afianzado, establecido con firmeza. Una institución política es un complejo de poder en el cual se cumple la adecuación de la conducta a reglas firmes, es decir en que la conformidad del comportamiento con las reglas se ha convertido en una configuración estable.

Al fin y a la postre, se puede caracterizar, en el sentido más general, el Estado o el gobierno como una forma de la dominación o del poder, estabilizada e institucionalizada. ${ }^{17}$

Después de una serie de análisis y comentarios sobre las diversas clasificaciones de las varias formas de gobierno, Friedrich propone la siguiente tipología:

1. Anarquía - dominación fragmentaria;

2. Dominación tribal de un rey-sacerdote;

3. Despotismo de tipo monárquico;

(Dominación sobre extensos territorios)

4. Oligarquía de una nobleza;

5. Oligarquía de los ricos;

6. Oligarquía de una clase sacerdotal _teocracia;

7. Democracia directa o inmediata; 
8. Tiranía;

9. Dominación burocrática bajo una monarquía hereditaria;

10. Gobierno de tipo parlamentarista;

(Gobierno por representantes elegidos;

a) Aristocracia - predominan la nobleza y la riqueza;

b) Democracia - abarca todas las clases sociales);

11. Gobierno presidencialista;

(gobierno mediante un presidente elegido y una representación popular elegida);

12. Dictadura militar;

(incluso el gobierno pretoriano);

13. Dictadura totalitaria.

De cada uno de estos tipos naturalmente que son posibles variadas formas; y además hay formas de transición entre dos tipos. Pero, en términos generales, Friedrich cree que la mayor parte de las formas de gobierno pueden ordenarse bajo esos trece tipos.

Ciertamente para el análisis de cuál sea el tipo de un cierto gobierno es necesario aprender cuál sea el grado del asentimiento general de que disfrute y la intensidad de ese asentimiento. En este análisis hay que precisar cuáles sean los grupos de población en los cuales el consenso esté más generalizado y resulte más intenso.

Un ulterior análisis del poder y de sus formas lleva al estudio del fenómeno de la "influencia". Las múltiples y variadas formas en que aparece la influencia y la importancia de ellas refuerzan el convencimiento de que no se puede pensar en el poder exclusivamente como un fenómeno de mando. El concepto de "poder" debe ser ampliado de manera que comprenda la caracterización de toda relación interhumana en la que un determinado grupo acomoda su comportamiento a los deseos de un individuo o de varios individuos. Con ello el dominador y los dominados se hallan ligados entre sí para la consecución de determinados valores y la puesta en práctica de unas ciertas tareas.

Por eso se puede designar al poder como la capacidad para la decisión de aquello que debe ser hecho en una determinada situación.

"Influencia" es sobre todo el poder que no se manifiesta como una fuerza de mando. Existe influencia cuando la conducta de B se acomoda a los deseos de $\mathrm{A}$ sin que A haya emitido ningún mandato para ello.. ${ }^{18}$

"La amante de un príncipe, el sirviente de un gran señor, el padre confesor de un político, el secretario de un diputado, y muchos otros pueden ejercer influencia sobre determinadas personas." En una asamblea legislativa determinados miembros de ella ejercen una influencia mayor que la de otros;

18 Véase Frotz J. Roethlisberger, Management and Morals, 1941. 
en un orden democrático hay grupos de intereses que influyen sobre el gobierno y sobre los órganos del mismo; un parlamento o una comisión parlamentaria puede influir poderosamente sobre los órganos responsables de la política exterior.

$Y$ son muchas las maneras de ejercer la influencia: medios psíquicos, como la fascinación que emana de una vigorosa personalidad; el poder de convencimiento de un hombre de inteligencia superior; el encanto de un individuo amable; todos estos son ejemplos psíquicos de influencia.

Hay que registrar también el fenómeno de la importancia que tiene el factor económico en la influencia de grupos.

Los factores psíquicos coercitivos suelen desempeñar un gran papel en muchas relaciones internacionales, por ejemplo, la influencia del temor de un Estado pequeño y débil frente a un vecino con un vigorosísimo ejército.

Incluso el fulano más cruel experimenta a veces el temor de la reacción que su conducta pueda provocar en el cuerpo social.

A veces la influencia, en sus variadas formas y muy diversos tipos, se ejerce de manera positiva, es decir, produciendo una adecuación de la conducta de los influidos a los deseos del influyente. Pero otras veces, con extraordinaria frecuencia, su modo de acción es negativo, es decir, la influencia impide que el influido se conduzca de una determinada manera.

En general, aunque no universalmente en términos absolutos, la influencia se manifiesta predominantemente en favor del orden de cosas que existen. Sin embargo, puede a veces manifestarse muy activa en el crecimiento de los movimientos revolucionarios.

Muchas veces la influencia de la opinión pública sobre un gobierno no suele manifestarse en hechos externos, porque las gentes del gobierno anticipan mentalmente cuál sería la reacción del pueblo si no siguiesen la línea de la opinión pública predominante.

Hay un sin fin de modos de clasificar los fenómenos del poder: según su origen; según la fuerza de la coerción o del consentimiento; según los signos externos visibles y sus efectos, como mandatos, negociaciones, etc. Ahora bien la influencia no se debe tratar como un modo de poder porque habitualmente la influencia se da en todas las formas del poder.

Claro que, sin embargo, hay situaciones en las cuales la influencia podria ser considerada como una forma de poder, así por ejemplo, cuando no se manifestado ninguna fuerza de mando. Pero generalmente la influencia se da en casi todas las formas de mando, de una u otra manera.

Especial mención merece la influencia consistente en la capacidad de resistencia frente a un determinado poder. Este fenómieno se produce incluso en las más poderosas dictaduras. Hay un nivel de tolerancia, que incluso el más desalmado autócrata no puede rebasar sin poner en peligro su mando, incluso su propia persona. 
Friedrich establece los siguientes enunciados fundamentales sobre la influencia:

Primero: la influencia puede fundarse sobre cualquier valor común al influyente y a los influidos.

Segundo: La influencia se aumenta cuando disminuye la seguridad o el sentimiento de la misma, sencillamente porque hày una coincidencia entre quien ejerce y quien recibe la influencia.

Tercero: La influencia disminuye cuando la relación entre quien la ejerce y los destinatarios de ella se hace pública. El hecho de que se mantenga en secreto desempeña un gran papel en casi todas las formas de influencia. Claro que resulta muy difícil, casi imposible, mantener en secreto todas las modalidades de la influencia. Es posible que se sepa que existen influencais, pero que no se conozcan los detalles del ejercicio de las mismas.

Cuarto: La influencia trata de convertirse en poder formal, tan pronto como su existencia es conocida públicamente. Hay varias modalidades de la influencia: material o económica, personal e intelectual.

Hay muchas formas y manifestaciones de la influencia económica, que nada tienen que ver con la corrupción.

La influencia personal se apoya sobre el sentimiento. La inspiración desempeña en ella un gran papel, sobre todo en los casos de un liderazgo carismático. En la influencia personal de A sobre $B$ ocurre a menudo que $B$ anticipa cual sería la reacción de $A$ respecto de cierto comportamiento diferente del deseado por A. En este tipo de influencia vienen en cuestión sentimientos muy diversos: amor, odio, veneración y rencor, confianza, desconfianza, etc.

$\mathrm{Y}$, finalmente, tenemos el tipo de influencia intelectual, que se apoya en una gran capacidad o en un saber superior. Así acontece que un ministro de alto rango mental influye sobre el rey; que subordinados con grandes luces mentales y cultura excepcional influyen sobre sus superiores; o que intelectuales sin ningún cargo dejan sentir su influencia sobre políticos menos talentosos.

En la influencia política hay que considerar muy especialmente el reino de la opinión pública y de la propaganda. Muchas relaciones recíprocas entre gobernantes y gobernados quedarían como algo incomprendible, si no se prestase especial atención al fenómeno de la influencia. ¿Por qué se comporta el pueblo tal como desean los gobernantes, incluso cuando los gobernantes no disponen de medios coercitivos y el pueblo obedezca sólo de mala gana? ¿Hasta dónde llega la tolerancia de los gobernantes y de los gobernados? ¿Por qué y bajo qué condiciones los gobernantes anticipan mentalmente las reacciones de su pueblo? Este es un campo incitante para la la investigación y constituye una tarea que la ciencia política debe emprender muy en serio. 
La influencia de todos los tipos ejerce un gran papel en las deliberaciones para llegar a un acuerdo o a un compromiso.

Después estudia Friedrich el hecho de la autoridad. Pero emplea esta palabra no en el sentido más habitual y corriente como designación de una persona investida de poderes legítimos dentro de cierta esfera, antes bien, la usa en un sentido diferente. En ese sentido, autoridad significa que en una persona o en una cosa (por ejemplo, un diccionario) reside un valor acrecentado o en aumento. Llega a esta acepción mediante un análisis semántico del verbo latino augere que significa ampliar o multiplicar, del cual provino la palabra auctoritas. Un acto de poder adquiere auctoritas cuando es justificable mediante la razón, o cuando representa la puesta en práctica de algún valor hacia el cual se encamina la intencionalidad de dicho acto.

Hobbes y Rousseau, al igual que otros muchos, afirmaron que la voluntad soberana es la fuente de todo derecho. Por el contrario la tradición jurídica inglesa y norteamericana hace hincapié en la antigua concepción de fundamento estoico de que la ratio, la razón, tiene una importancia decisiva para la autoridad de una norma jurídica.

Como subraya certeramente T. D. Weldon, ${ }^{19}$ la constatación de que la persona que emite un mandato tiene autoridad en el sentido expresado, constituye una de las razones para obedecer lo que ordene dicha persona.

En fin de cuentas, hay autoridad cuando existe la capacidad de conseguir el asenso por virtud de una fundamentación razonable. Así pues, autoridad no es una nota o forma del poder o de la dominación en sí, antes bien una cualidad de determinados dominadores o gobernantes; o, mejor dicho, una cualidad razonable de lo mandado. Friedrich insiste mucho sobre este punto, para que quede claro que lo que él hace no son observaciones psicológicas, sino que es más bien una caracterización ontológica.

Es obvio que cuando lo mandado tiene autoridad origina una forma de poder consensual.

Mientras que, como ya se ha dicho, la autoridad se diferencia del poder y de la fuerza, en cambio de todo lo dicho se deduce claramente que la capacidad de emitir manifestaciones autoritativas, esto es, de conseguir valor para las determinaciones hechas, de modo que éstas cobren plenitud de sentido para sus destinatarios, se halla en estrecha relación con los fenómenos del poder, sobre todo del poder consensual.

Frecuentemente los tiranos han ejercido un poder pavoroso, pero con poca o ninguna autoridad, mientras que hombres con valiosas convicciones, los cuales se hallaban bajo el poder de tales tiranos, poseían gran autoridad sin mucho poder.

Con el propósito de precisar todavía más el concepto de la autoridad, Friedrich da la siguiente definición: la autoridad es una capacidad para

19 Véase Thomas D. Weldon, The Vocabulary of Politics, 1953. pp. 50-56. 
suministrar una fundamentación razonada sobre la base de intuiciones, valores, convicciones, intereses y necesidades de una comunidad.

Justicia en sentido político es la suma y compendio de todo aquello que se halla de acuerdo con los valores, intuiciones y convicciones de la comunidad y que es, por eso, especialmente también, lo que según una opinión autoritativa cumple un requerimiento de igualdad.

Entonces resulta que la "autoridad política justa" es una expresión ạbreviada del hecho de que la autoridad, entendida como capacidad de fundamentación comunal, representa el eslabón de enlace entre poder y justicia.

La autoridad implica una armonía con la verdad; pero entendiendo la verdad no sólo en el sentido restringido de la ciencia, por ejemplo, de la matemática, sino con una amplitud mucho mayor, porque son muchas las diversas formas del ser $\mathrm{y}$, por consiguiente, los diversos tipos de verdad. De aquí, que se pueda hablar de "verdadera autoridad" y de "falsa autoridad".

La autoridad puede ser asegurada tan sólo cuando cabe que lo que se manda y afirma sea fundamentado y defendido con plenitud de sentido.

Otra cuestión diferente de las tratadas hasta aquí es el problema de la legitimidad. Este problema consiste en cuál sea el fundamento de la pretensión de un gobierno para regir a un pueblo o a una nación.

Nos encontramos con muchas y diversas opiniones sobre este punto. En épocas primitivas encontramos la creencia mágica en la ascendencia divina del gobernante. También la creencia en un origen fundado en el parentesco de la sangre, la cual considera el derecho al gobierno como un derecho de propiedad que se trasmite por sucesión.

Así mismo el pensamiento de que el gobierno es el símbolo de Dios en la tierra.

Hallamos también la creencia de que un sistema de mando que ha regido durante larguisimo tiempo y se ha convertido en una norma consuetudinaria está justificado que persista de acuerdo con una tradición inmemorial. Según Platón sólo los filósofos tendrían justificada pretensión para gobernar, tesis que es diametralmente contradicha por Kant. En el presente predomina la idea de que la legitimidad se funda sobre la elección. De acuerdo con esto se considera legítimo el sistema de gobierno instituido por una asamblea constituyente.

Sin duda tiene mucha importancia el hecho de que la mayoría de los sometidos a un determinado gobierno tengan la convicción de que ese gobierno se apoya sobre un buen título jurídico, es decir, la convicción de que es legitimo.

La legitimidad no debe confundirse con la legalidad. La legalidad consiste en que el gobierno obre de acuerdo con las leyes del derecho positivo. Es obvio que puede haber un gobierno ilegitimo cuya conducta se ajuste a los requisitos más rigurosos de la legalidad. La legitimidad concierne al 
origen y fundamento primario del poder público. $Y$, a la inversa, puede darse el caso de un gobierno perfectamente legítimo cuyo comportamiento no esté de acuerdo con los requisitos de la legalidad.

Entre los autores contemporáneos, quien ha dado una gran importancia y largo alcance a este tema de la legitimidad es el italiano Guglielmo Ferrero, mostrándose partidario de la legitimidad democrática. ${ }^{20}$

Como es bien conocido, Max Weber ${ }^{21}$ habla de tres clases de legitimadad: la tradicional; la racional legalista; y la carismática. Friedrich clasifica los tipos o formas de legitimidad como sigue: 1) Legitimidad religiosa; 2) Legitimidad filosófico-jurídica; 3) Legitimidad tradicional; y 4) Legitimidad pragmática.

La legitimidad religiosa se clasifica según los diversos credos religiosos (cristiano; confucionista, mahometano, etc.).

La legitimidad tradicional se apoya sobre el uso o la costumbre de larga duración.

La legitimidad pragmática es la forma democrática consistente en el resultado de una elección. De una manera, a mi parecer no suficientemente justificada, Friedrich menciona otras formas de legitimidad pragmática como es, por ejemplo, el éxito en una guerra, porque garantiza la seguridad del orden, de la paz y del bienestar, etc.

Todas esas diversas formas de legitimidad tienen un denominador común, a saber: el hecho de que los gobernados en cada caso acepten como bueno el título de legitimidad aducido por el régimen que-los gobierna; y, por lo tanto, cualquiera de esos títulos, que se entiende aceptado por los gobernados, da origen a un poder consensual.

Es curioso recordar que Tomás de Aquino, ${ }^{22}$ al igual que otros muchos filósofos medievales y del Renacimiento, fundan la legitimidad sobre un supuesto contrato en el cual el pueblo establece el gobierno que prefiere y pacta con las personas designadas para el ejercicio del poder; y más adelante razonando que la esencia del contrato radica en el consentimiento, admite como sustituto de tal contrato formalmente celebrado el hecho del público asenso del pueblo respecto de un determinado régimen del gobierno; interpretando ese asenso como una especie de tácito consentimiento.

De todo lo dicho se sigue que la legitimidad es posible tan sólo cuando efectivamente en una sociedad se dan de modo predominante las condiciones de que un determinado título de gobierno es valioso, esto es, ajustado a derecho. Entiéndase que con eso de "ajustado a derecho" no se pasa de la legitimidad a la legalidad, porque el ajuste a derecho se pide sólo respecto

\footnotetext{
“ 20 Véase Guglielmo Ferrero, en trad. al inglés, The Principles of Power, 1942, cap. IV. 21 Véase nota 14.

22 Véase las obras mencionadas en la nota $10 \mathrm{y}$, además, Luis Recaséns Siches, La filosofia del derecho de Francisco Sudrez, con un estudio previo sobre sus antecedentes en la patristica y en la escolástica, caps. VII y XII.
} 
del título para gobernar. Claro que si no existe una mayoría que profese esta convicción, entonces propiamente no hay legitimidad y nos encontramos ante una situación de anomia. Una auténtica situación de anomia existe sólo cuando ninguna medida ni ningún juicio de valor es reconocido por la generalidad de los sometidos al régimen de que se trate. Cuando las opiniones se encuentran divididas en una gran medida entonces puede hablarse más bien polinomia.

Cuando no hay una opinión mayoritaria sobre este punto, entonces nos encontramos con que no hay legitimidad.

Con respecto a la legitimidad se han formulado varias hipótesis.

La primera de ellas sostiene que el gobierno legitimo en iguales condiciones es mucho más eficaz que el no legítimo. En definitiva, esto viene a confirmar la importancia de la consensualidad en el poder, es decir, en el hecho de que el poder cuente con el consentimiento de los gobernados.

El segundo enunciado es el de que todos los gobernantes se afanan por encontrar un título satisfactorio de legitimidad para su régimen; y en el caso de que no la consigan, hay que notar el hecho de que se esfuercen en cambiar la idea dominante sobre el título de legitimidad, por otra diferente.

Por fin, el tercer enunciado sobre este punto es el de que la legitimidad de un gobierno refuerza el grado de obligación política de los ciudadanos. Cuando la convicción sobre la legitimidad es amplia y muy firme, entonces los gobernados se sienten más vigorosamente obligados a obedecer.

El partidario de la legitimidad democrática cree que todos los hombres tienen una igual capacidad para decidir correctamente quién debe gobernar. No sostiene desde luego de modo alguno que todos los hombres posean en igual medida capacidad para gobernar. Por el contrario, opina que las aptitudes de los hombres en este respecto son tan diferentes, que por eso no se puede dejar la elección del gobernante a la casualidad, que es lo que sucede en los regímenes hereditarios. $Y$ por tanto tampoco acepta ningún sistema plutocrático, puesto que la obtención de riqueza puede resultar fortuita. Pero sí sostiene que todos tienen derecho a igual voto para decidir sobre quién debe gobernar.

Pero algunos, ulteriormente, condicionan la legitimidad del gobernante al valor que sus actos de gobierno tengan. Así entre los antiguos chinos el emperador, a pesar de ser considerado como "hijo del cielo", debía probar su legitimidad produciendo el bienestar del pais.

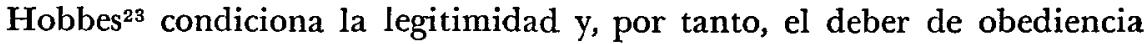
de los súbditos al hecho de que el gobernante suministre seguridad. Tanto que si no proporciona esa seguridad, pierde todo derecho al gobierno. "Los súbditos están obligados respecto del gobernante sólo en tanto en cuanto el gobernante tiene poder para protegerlos."

23 Véase Thomas Hobbes, Leviathan, 1651, cap. 21. 
Otro de los factores que contribuye a conceder legitimidad a un gobierno es su actitud para mantener la autodeterminación y la unidad nacionales.

En el proceso de legitimación democrática desempeñan un papel importante no sólo la consideración de las cualidades y aptitudes de los candidatos, sino también las finalidades, los propósitos y las políticas que cada uno de ellos intenta seguir. En este punto aparece el parentesco entre la legitimidad democrática y la burocracia.

De todo lo dicho se sigue la íntima relación entre la legitimidad y la idea de la justicia. La legitimidad es una forma especial de la justicia distributiva en la investidura de cargos públicos según los méritos.

Hay también un ligamen entre la legitimidad y la verdad; porque la legitimidad se funda en supuestas cualidades del gobernante en quien se reconoce ese título. Podrá tratarse no de una verdad absoluta, pero no obstante es posible saber que muchos enunciados son más verdaderos que otros. Esta posibilidad incluye todo cuanto se diga sobre la legitimidad. Pues también respecto de Ia legitimidad hay siempre diferencias de grado. Una determinada forma de gobierno posee una mayor legitimidad que otras, y lo mismo puede decirse respecto de los gobernantes individuales.

En el contexto de sus estudios sobre el poder, Friedrich se plantea el tema de la justicia política. No intenta emprender un estudio a fondo de la justicia en términos generales, antes bien tan sólo de lo que él denomina justicia politica.

Cabe poner en relación la justicia política con la idea de la justicia distributiva según Aristóteles. Y, a este respecto, Friedrich dice lo que ya manifesté yo en $1934,{ }^{24}$ a saber, que para determinar lo que corresponde a cada uno es necesario apelar a unos valores relevantes, bajo cuya luz descubriremos las igualdades que deben ser tomadas en cuenta, así como las desigualdades que deben reflejarse en un trato desigual. Porque la mera fórmula de tratar de igual manera a los iguales y de diferente manera a los diferentes implica la referencia a unos criterios axiológicos que se considera deben servir como base para establecer las equivalencias y para determinat las desigualdades $\mathrm{y}$, consiguientemente, el diverso tratamiento de los desiguales.

Este reconocimiento obliga a rectificar la representación habitual de la justicia como una persona con los ojos vendados, la cual establece relaciones de igualdad sin fijarse en absoluto en quiénes son las personas que vëngan en cuestión. Esto puede valer acaso para la justicia conmutativa; pero no para la justicia distributiva.

La justicia política implica el requisito de que debe ser evitada toda

24 Véase Luis Recaséns Siches, Los temas de la filosofia del derecho en perspectiva histórica y en la visión de futuro, 1934, pp. 90-110. 
arbitrariedad, pues la justicia distributiva debe fundamentarse sobre las valoraciones vigentes en la comunidad, mientras que el acto arbitrario responde a un mero capricho sin fundamento en las reglas aceptadas por la sociedad.

Otro de los requisitos consiste en que la justicia no puede exigir lo que resulte de imposible realización. Lo reconocieron así ya los antiguos al decir ultra posse nemo obligatur. De aquí, la justicia política no puede exigir la realización de actos heroicos, los cuales están al alcance tan sólo de unas pocas personas. Este es un punto sobre el cual yo he insistido desde hace varios decenios en mis páginas dedicadas a la estimativa jurídica. ${ }^{25}$

Cierto que en el reino de la política sucede que no siempre se puede decir con toda seguridad qué debe ser considerado como "imposible". Pero sobre esto, al igual que sobre otras muchas cosas, en definitiva deciden las valoraciones predominantes en la sociedad que venga en cuestión.

La comparación entre la justicia política y la injusticia política no aparece como la contraposición entre dos magnitudes absolutas, es decir, no constituye una alternativa entre dos puntos absolutos, sino más bien la diferencia entre lo más y lo menos justo.

Friedrich ha hablado de valoraciones y convicciones predominantes en una sociedad; pero esto plantea el problema de saber cuándo y hasta qué punto podemos considerar unas valoraciones como preponderantes. Según Friedrich, aquí debe tomarse en cuenta la autoridad y la legitimidad; pues en la perspectiva política no se puede separar la injusticia de la autoridad ni de la legitimidad.

A este respecto se plantean las siguientes preguntas: 1) ¿Posee aquel que afirma que existe una concordancia con la justicia, autoridad para su enunciado? 2) ¿Posee él la situación o el cargo en cuya virtud su enunciado debe ser considerado como legítimo? Autoridad, significa, según se explicó ya, que quien tiene el poder sea capaz de explicar y fundamentar razonablemente lo que él manifiesta. La autoridad representa el punto, el eslabón de enlace, entre poder y justicia.

Friedrich advierte que por el hecho de que él se refiera a las valoraciones y convicciones predominantes en una comunidad, no por ello debe considerársele representante del subjetivismo relativista. Porque a despecho de tantas y tantas divergencias y controversias hay el denominador común de un afanarse por la justicia $y$, en fin de cuentas, concordancias fundamentales sobre este tema. Por otra parte, debe tenerse en cuenta la dimensión dinámica de las realidades a las cuales y para las cuales se aplica la justicia, dinamismo que inevitablemente se contagia a las mismas ideas de justicia. Por eso no debe asustarnos que en . este campo nos encontramos con modificaciones y cambios, pues ello es inherente a la vida social misma. La jus-

${ }^{25}$ Véase también Àrnold Brecht, Political Theory, 1959, p. 97 ss., 417 ss. 
ticia no es algo "dado", sino que, por el contrario, es una tarea dinámica propuesta a los hombres, los cuales se esfuerzan por acercarse a las exigencias de tal idea en combinación con los materiales sobre los cuales esta idea se proyecta.

El reconocimiento de las variedades y de las transformaciones no implica una actitud de subjetivismo escepticoide, sino más bien es un darse cuenta de la relacionalidad de la justicia con cada una de las situaciones reales diversas y en mutación. Justicia perfecta podría darse tan sólo en una sociedad plenariamente estática.

La realización aproximada de la justicia es un proceso dinámico que se desenvuelve en el tiempo y que está dominado por fuerzas, las cuales pugnan por su realización dentro del marco general del orden político. Pero por debajo de todos esos hechos hay en fin de cuentas la representación de que las acciones y decisiones políticas debieran ser justas, ciertamente en el sentido en que ha quedado definida la justicia. Así entendida, la búsqueda de la justicia introduce un elemento dinámico en el orden jurídico; elemento dinámico que constantemente lleva a la modificación de dicho orden. Tal cambio tiene lugar en concordancia con los nuevos grupos que surgen en la sociedad y con los valores a los que esos grupos están adheridos y por cuya realización pugnan.

Si se hace depender la justicia de una decisión mayoritaria del pueblo, con esto los problemas de la justicia no quedan resueltos, sino sencillamente colocados sobre otro plano.

El problema de la justicia puede ser resuelto solamente si se puede reafirmar que en una sociedad libre hay un número suficiente de personas con sentido de responsabilidad, las cuales no sólo buscan la conciliación de los intereses opuestos en pugna. sino que, al mismo tiempo, se afanan por una "síntesis" superior para superar los intereses particulares y para establecer un compromiso equilibrado entre valores, creencias y convicciones divergentes. Pues sólo entonces se podrá realizar de una manera permanente y progresiva la tarea, que se plantea una y otra vez, de comparar a los hombres desde el punto de vista de los valores y convicciones aceptados por la generalidad de la sociedad. Y esto puede lograrse mediante una especie de diagonal en el paralelograma de las fuerzas entre los intereses rivales. Pues aun cuando hay numerosas leyes que no son otra cosa más que compromisos entre intereses particulares, hay, sin embargo, también otras leyes que apuntan al servicio de los intereses comunes y respecto de cuya justicia se producen en ocasiones debates apasionados.

De todo lo expuesto se sigue que la justicia excluye lo que no es verdadero, lo arbitrario y lo imposible. Una operación política es justa cuando se apoya sobre el juicio cuidadoso de las personas a las cuales se refiere y cuando compara y clasifica a esos hombres de acuerdo con las valoraciones 
predominantes en la comunidad. Tal concepción de la justicia contribuye a suavizar las tensiones entre el poder y la autoridad, y a una visión más profunda en el tema de la legitimidad de los gobiernos y de las acciones de éste.

\section{Consideración final}

Todos los análisis producidos por Geiger y por Friedrich contribuyen a mostrar hasta la saciedad cuán complicadas son las relaciones entre derecho y poder, y los muchos matices que en las mismas se dan.

Después de haber transitado por todos los análisis de ambos autores, siguen siendo correctas las afirmaciones iniciales: $A$ ) Que no hay intrínsecamente una oposición entre derecho y poder. B) Que lo que se opone es el poder injusto o arbitrario al poder jurídico y justo. $C$ ) que todo derecho necesita para realizarse el apoyo de un poder. $D$ ) Que el poder al servicio del derecho y de la justicia constituye un valor.

Pero el estudio de los análisis y la exposición que antecede ponen de manifiesto cuán complicado es el tema del poder y el sinnúmero de puntos que es necesario esclarecer sobre él.

LuIS RECASÉNS Siches

Instituto de INVESTIGACiones Filosóficas

Universidad Nacional Autónoma de México 